\title{
Influence of Non-Productive Operations on Product Quality
}

\author{
Peter Eniko ${ }^{1}$ - Mirko Soković ${ }^{2}$ - Davorin Kramar ${ }^{2}$ \\ 1 Difa d.o.o., Slovenia \\ 2 University of Ljubljana, Faculty of Mechanical Engineering, Slovenia
}

This paper addresses the study of piston bore machining. Within the framework of an experimental investigation single and combined effects and related reproducibility of such parameters on bore geometry and surface finish were investigated. Experiment planning and process modelling were performed by design of experiments (DOE) methodology. The experimental part was carried out in a regular production which is affected by non-productive operations that influence product quality. Based on the reaming process state of the art review and previous industrial experiences feed rate and spindle speed were identified as key productive operation factors in achieving bore cylindricity and surface roughness. Non-productive operations, such as clamping, washing and degreasing of the workpiece that negatively impacted results, were identified during experimental work with scanning electron microscope (SEM) analysis and pattern recognition in statistical process control (SPC) control chart. Negative impacts of non-productive operations were minimized with corrective actions. Regression analyses give models for both responses under consideration, namely bore cylindricity and surface roughness, and are at adequate confidence level. Experiments conducting, analysis and corrective actions are included in optimization strategy model which is schematically shown and interpreted in discussion.

Keywords: DOE, cylindricity, surface roughness, washing, degreasing

Highlights

- $\quad$ For case study machining of piston bore in regular production which is affected by non-productive operations is analyzed.

- Surface cleanliness effect on measurement reproducibility is defined and minimized with corrective actions.

- $\quad$ Clamping device weakness is identified with pattern recognition in SPC control chart.

- $\quad$ Results show influence of non-productive operations on product quality and are schematically summarized in optimization strategy model.

\section{O INTRODUCTION}

Small batch production is mainly, due to the competitiveness of the market, oriented to achieve the required specifications with minimal manufacturing processes using standard cutting tools. Costume-made hydraulic valves are one of the unique cases of small batch production in combination with high tolerances requirements [1]. Honing represents the manufacturing process which enables achieving final geometric requirements for valve's cylinder bore and requires pre-processing on computer numerical control (CNC) machining centre with successive cutting processes drilling, milling and reaming. Specifications of the piston bore of the hydraulic valve housing prescribe cylindricity $/ \mathrm{o} \leq 12 \mu \mathrm{m}$ and surface roughness $R a \leq 1.6 \mu \mathrm{m}$ after reaming and cylindricity $/ \circ / \leq 3 \mu \mathrm{m}$ and surface roughness $R a \leq 0.4 \mu \mathrm{m}$ after honing.

This paper deals with reaming process quality improvement. Experiment planning and process modelling were performed by design of experiments (DOE) methodology [2]. Measuring method for bore cylindricity was defined as suggested in [3] and [4] and surface topology with mean roughness parameter $R a$ [5]. Within the framework of an experimental investigation single and combined effects, as well as related reproducibility, of such parameters on bore geometry and surface finish were investigated.

Factors that have been identified as key to achieve specifications (bolded factors in Fig. 1) have been studied within the experimental work. Authors in other reaming processes optimization studies investigated spindle speed $n$ and feed rate $f$ as numeric control factor [6] to [9]. In this study feed rate and spindle speed were recognized as the key productive operation factors as well.

Studies on CNC machining centres clamping devices field [10] and [11] present weaknesses and strengths of clamping devices to achieve the desired results of experimental work. Studies as Theodoris and Koutroumbas [12] and Hassan and Basksh [13] are focused on pattern recognition in Statistical Process Control (SPC) control charts.

The key non-productive operation factors that were analysed in this study were clamping device lack of rigidity and effect of surface cleanliness on measurements reproducibility. Clamping device weakness was minimized with focusing on only one (of three) clamping nest. Surface cleanliness impact was analysed with SEM analysis and was minimized with additional washing and degreasing. 


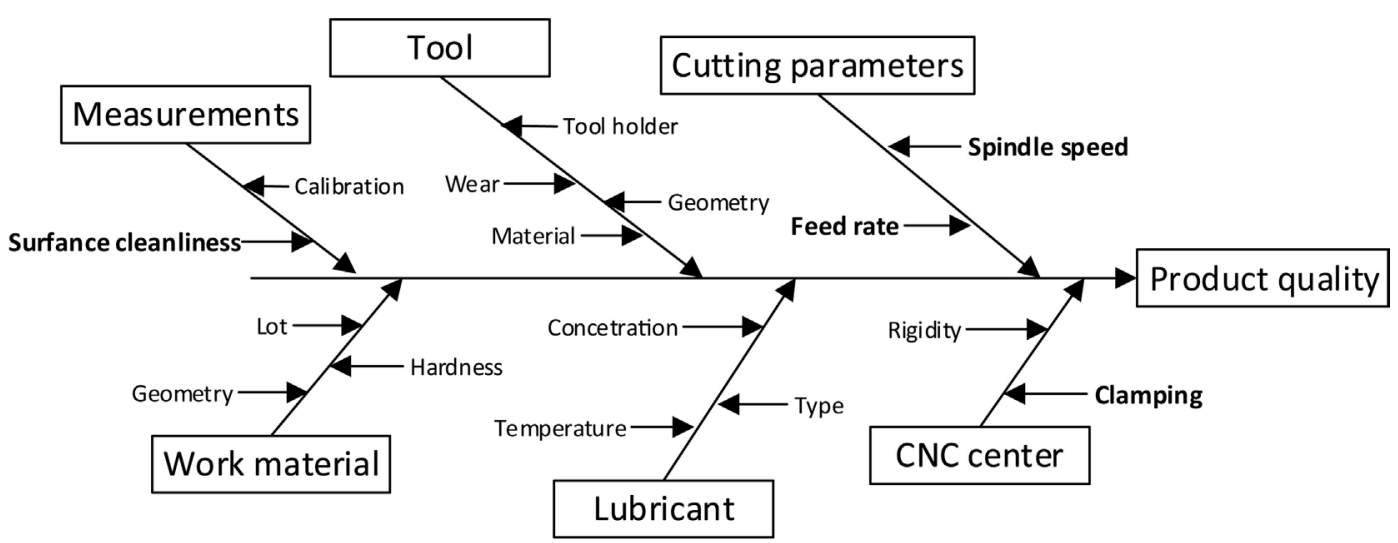

Fig. 1. Key factors for achieving required product specification

Impacts of the drill bit and the milling cutter tool life, the material of the cutting tool, the workpiece material, cutting tool holder, the geometry of the workpiece, and the characteristics of lubricant were neglected during research. They were neglected because the experiments were carried out on the same type of product, i.e. material and batch were the same and the same cutting tool was used. Drilling and milling parameters settings were not changed during experimental work.

Experiments conducting, analysis and corrective actions were included in optimization strategy model in discussion.

\section{APPROACH AND METHOD}

Experimental part includes a clear identification of the problem statement, selection of control factors and their respective levels and ranges. To improve production quality systematic approach with the use of DOE methodology has been selected. First with preexperiments the region of operability for reaming i.e. reamer's technological window was determined using regular procedure [14]. After pre-experimental runs effect of clamping device weakness and inadequate surface cleanliness is presented. With exclusion of these noise factors, using DOE controlled factors significance on product quality was defined.

\subsection{Technological Window Determining}

Region of operability for reaming was determined with pre-experiments using regular procedure. Reamer with in-operation time (tool life) $t=250 \mathrm{~min}$ was utilised. Experiments were started from the existing production parameters settings (bold point in Fig. 2; spindle speed $n=350 \mathrm{rev} / \mathrm{min}$, feed rate $f=100 \mathrm{~mm} / \mathrm{rev}$ ) and carried out in a diagonal direction of the $n / f$ diagram. Extreme values of technological window (rectangle in Fig. 2) were determined with a point where machining conditions were still acceptable. The criterion for determining the technological window was set on values $30 \%$ lower than prescribed with reaming process specifications. Cylindricity tolerance was set on $/ 0 /<8 \mu \mathrm{m}$ and surface roughness was set on $R a<1.1 \mu \mathrm{m}$. The goal of using such criteria was determination of more robust region of operability that would also be used for optimization experiments for further researches. Resulted technological window limits shown in Fig. 2 are listed in Table 1, as first (-1) and second (1) level of the reaming parameters.

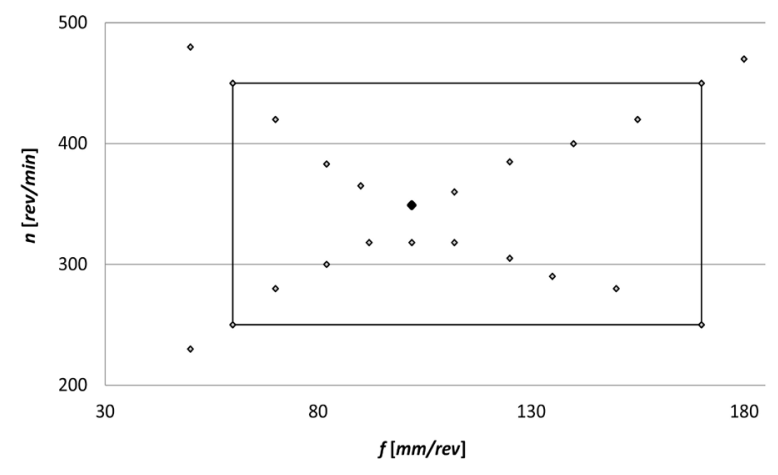

Fig. 2. Determination of technological window for reaming process

\subsection{Experimental Set Up}

The experimental part was carried out in regular production and thus includes real production noise factors, which are difficult to simulate in laboratory testing. Control factors and their levels were chosen on a base of pre-experiments and review of the 
Table 1. DOE and experimental results

\begin{tabular}{|c|c|c|c|c|c|c|c|c|c|c|}
\hline \multirow{3}{*}{$\begin{array}{c}\text { Exp. } \\
\text { No. } \\
1\end{array}$} & \multirow{2}{*}{\multicolumn{2}{|c|}{ Coded level }} & \multicolumn{2}{|c|}{ Actual setting values } & \multicolumn{2}{|c|}{ After CNC } & \multicolumn{2}{|c|}{ After washing } & \multicolumn{2}{|c|}{ After degreasing } \\
\hline & & & $\underset{[\mathrm{mm} / \mathrm{rev}]}{f}$ & $\begin{array}{c}n \\
{[\mathrm{rev} / \mathrm{min}]}\end{array}$ & $\begin{array}{c}\text { Cylindricity } \\
{[\mu \mathrm{m}]}\end{array}$ & $\begin{array}{c}R a \\
{[\mu \mathrm{m}]}\end{array}$ & $\begin{array}{c}\text { Cylindricity } \\
{[\mu \mathrm{m}]}\end{array}$ & $\begin{array}{c}R a \\
{[\mu \mathrm{m}]}\end{array}$ & $\begin{array}{c}\text { Cylindricity } \\
{[\mu \mathrm{m}]}\end{array}$ & $\begin{array}{r}R a \\
{[\mu \mathrm{m}]}\end{array}$ \\
\hline & -1 & -1 & 60 & 250 & 9.37 & 0.8 & 6.18 & 0.6 & 4.6 & 0.4 \\
\hline 2 & -1 & -1 & 60 & 250 & 6.16 & 1.3 & 7.99 & 1.3 & 4.80 & 1.2 \\
\hline 3 & -1 & -1 & 60 & 250 & 12.06 & 0.9 & 8.52 & 1.5 & 6.39 & 0.8 \\
\hline 4 & -1 & 1 & 60 & 450 & 6.04 & 0.9 & 8.26 & 0.6 & 5.3 & 0.6 \\
\hline 5 & -1 & 1 & 60 & 450 & 12.73 & 1.3 & 6.43 & 1.3 & 6.04 & 1.3 \\
\hline 6 & -1 & 1 & 60 & 450 & 14.53 & 1.9 & 8.83 & 1.7 & 8.53 & 1.4 \\
\hline 7 & 1 & -1 & 170 & 250 & 9.06 & 1.2 & 7.44 & 1.1 & 5.5 & 0.9 \\
\hline 8 & 1 & -1 & 170 & 250 & 6.75 & 0.8 & 8.02 & 1.1 & 5.30 & 0.7 \\
\hline 9 & 1 & -1 & 170 & 250 & 9.81 & 1.3 & 7.33 & 1.1 & 6.18 & 0.9 \\
\hline 10 & 1 & 1 & 170 & 450 & 14.08 & 1.3 & 7.09 & 1.3 & 6.1 & 1.1 \\
\hline 11 & 1 & 1 & 170 & 450 & 13.94 & 1.7 & 8.72 & 1.8 & 6.10 & 1.6 \\
\hline 12 & 1 & 1 & 170 & 450 & 7.27 & 1.9 & 9.02 & 1.9 & 7.22 & 1.7 \\
\hline
\end{tabular}

reaming process studies. Experiments were carried out using $\mathrm{L}_{12}$ orthogonal array and analysed with ANOVA. In the experimental work the effects of reamer's tool life, cutting parameters and the part position in the clamping device on the cylindricity and surface roughness of the piston bore were studied. Experiments were carried out at ambient temperature $T=23^{\circ} \mathrm{C}$ with standard reamer DIN $8094 \mathrm{~B}$ with diameter of $11.9 \mathrm{~mm}$. Control factors - parameters and their values (Table 1) were determined by preexperiments for technological window determining and constitute an adequate range of parameters, which allow achieving the required specifications.

Experiments were carried out on Mori Seiki machine tool equipped with the option of tool life monitoring, which allows measurements of tool inoperation time in minutes. The workpiece material was C45E with dimensions of $70 \mathrm{~mm} \times 100 \mathrm{~mm} \times 100 \mathrm{~mm}$. Reamer tool operation time was $t=250 \mathrm{~min}$. The goal of using such tool was to get some conclusions that would present a base for further optimization researches that would not include only a new tool.

\subsection{Bore Cylindricity and Roughness Measuring}

Piston bore cylindricity measurements were carried out using Tayloround measuring device. For each specimen four roundnesses that define cylindricity at different bore positions together were recorded. To characterize surface roughness surface topology parameter $R a$ was used. Measurements were carried out using MarSurf roughness tester. For each specimen four profiles at four different piston bore positions were recorded.

\section{EXPERIMENTAL RESULTS}

Bore cylindricity and average surface roughness $R a$ resulted during machining of piston bore was measured after the experiments. The experimental results are given in Table 1. The correlation between the control factors and results of piston bore machining were obtained with multiple regressions. A multiple analysis of variance (ANOVA) was used for identifying the factors significantly affecting the preference measures, cylindricity and surface roughness after machining. $f$

\subsection{Measurement Reproducibility}

Experiments were carried out using $\mathrm{L}_{12}$ orthogonal array and analysed with ANOVA. Bore cylindricity and average surface roughness $R a$ resulted during machining of piston bore was measured after the experiments. The experimental results are given in Table 1. In order to define source of measurements deviation SEM analysis of surface cleanliness was performed. Impact of surface cleanliness was minimized with additional washing and degreasing.

\subsubsection{Measurements after CNC Machining}

A multiple analysis of variance (ANOVA) was used for identifying the factors significantly affecting the preference measures: cylindricity and surface roughness after machining on $\mathrm{CNC}$ centre. At this stage none of the controlled factors was recognized as significant and no regression model could be defined. Due to relative large measurements dispersion 
(Table 1) investigation on factors that affect bore quality, and was at very beginning neglected, was repeated. With deeply cause and effect (Fig. 1) investigation surface cleanliness was recognized as the key non-productive operation factor that impacts measurements reproducibility. SEM analysis was chosen as an appropriate method to study the surface cleanliness. During investigation with SEM analysis cleanliness of the bore surface was recognized as inadequate (Fig. 3a). SEM analysis shows presence of relatively big particles on the surface that impact measurement reproducibility. Regarding on these conclusion washing, with industrial washing machine, of all samples was performed.

a)

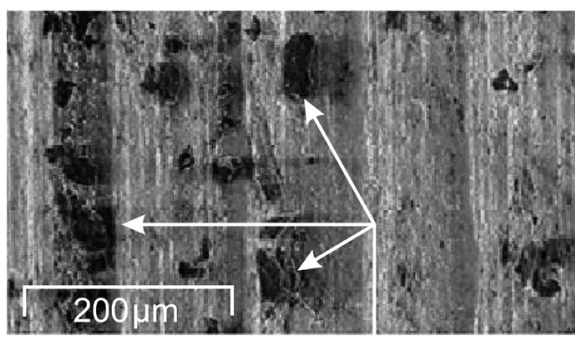

metal and emulsion machining leftovers

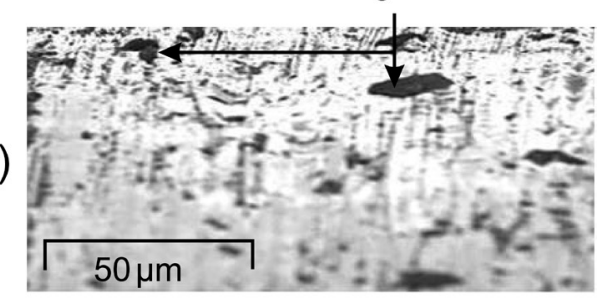

C)

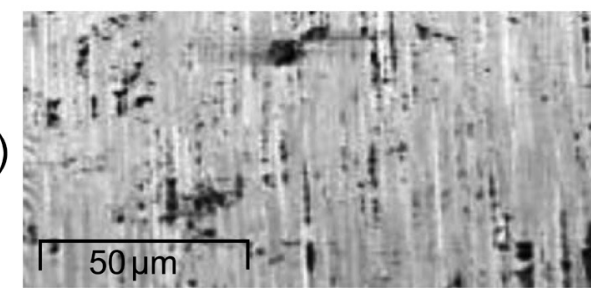

Fig. 3. Results of bore surface SEM analysis; a) after CNC; b) after washing; c) after degreasing

\subsubsection{Measurements after Washing}

After washing of all samples measurements and ANOVA were repeated (Table 1). Measurements after washing significantly differ from measurements after CNC machining (Table 2) which identify cleanliness of bore surface as the main impact on measurement reproducibility. ANOVA of measurements after washing did not recognize any factor as significant as well and consequently none regression model could be defined. SEM analysis of bore surface was repeated in order to confirm if there is still some noise effect on measurements (Fig. 3b). SEM analysis confirmed that there are still some smaller particles and lubricant leftovers that could have a negative impact on measurements reproducibility.

Table 2. Derogations proportion

\begin{tabular}{ccccc}
\hline \multirow{2}{*}{$\begin{array}{c}\text { Exp. } \\
\text { No. }\end{array}$} & \multicolumn{5}{c}{ Difference [\%] } \\
\cline { 2 - 5 } & After CNC / after washing & After washing / after degreasing \\
\hline 1 & 34 & 19 & 26 & 38 \\
\hline 2 & 23 & 4 & 40 & 11 \\
\hline 3 & 29 & 40 & 25 & 47 \\
\hline 4 & 27 & 32 & 36 & 8 \\
\hline 5 & 49 & 4 & 6 & 4 \\
\hline 6 & 39 & 8 & 3 & 20 \\
\hline 7 & 18 & 12 & 26 & 18 \\
\hline 8 & 16 & 23 & 34 & 36 \\
\hline 9 & 25 & 15 & 16 & 18 \\
\hline 10 & 50 & 4 & 14 & 15 \\
\hline 11 & 37 & 8 & 20 & 11 \\
\hline 12 & 19 & 0 & 20 & 13 \\
\hline
\end{tabular}

\subsubsection{Measurements after Degreasing}

All samples were degreased at this stage and measurements were repeated. Investigation of cleanliness of the bore surface was performed with SEM analysis and results confirm that adequate surface cleanliness was reached (Fig. 3c).

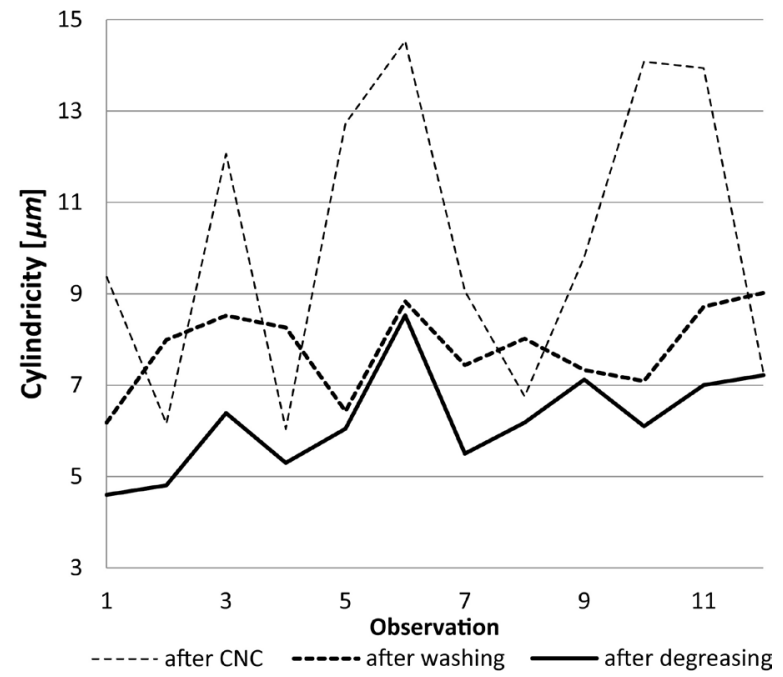

Fig. 4. Cylindricity measurements comparison graph 


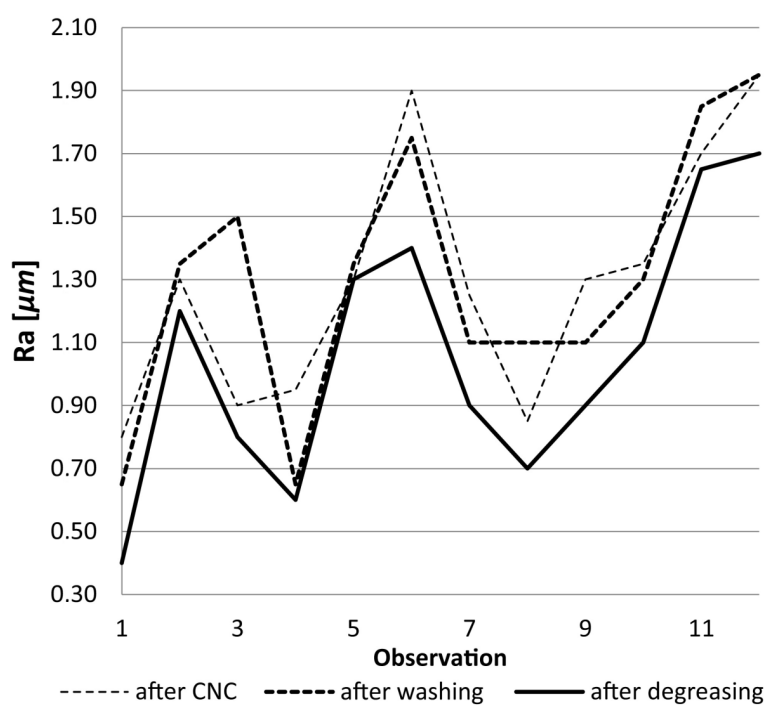

Fig. 5. Surface roughness measurements comparison graph

Figs. 4 and 5 show comparison between all measurements, it is obvious that measurements after $\mathrm{CNC}$ machining, after washing and after degreasing deviate drastically on the same sample (Table 2). Deviations within bore cylindricity measurements (Table 3) are greater than surface roughness which confirms large effect of surface cleanliness on cylindricity measurements reproducibility. Measurements after degreasing give best results and represent results that are reliable for research. ANOVA of measurements after washing still could not recognize any factor as significant and no regression model could be defined. Before making conclusions on controlled factors significance, additional researches on reliable data are needed.

\subsection{Clamping Device Weakness}

The existing clamping device allows mounting of three pieces, as shown in Fig. 6. Cylindricity /o/ graph (after degreasing) in Fig. 4 demonstrates the shortcoming of the clamping device. Shortcomings are evident as trend deviations of measurements of three consecutive samples. The results show that only the first nest ensures an adequate rigidity, allows the desired results and ensures reproducibility of the measurement (nest no. 1 in Fig. 6). Nests no. 2 and 3, due to poor rigidity, do not allow adequate reproducibility.

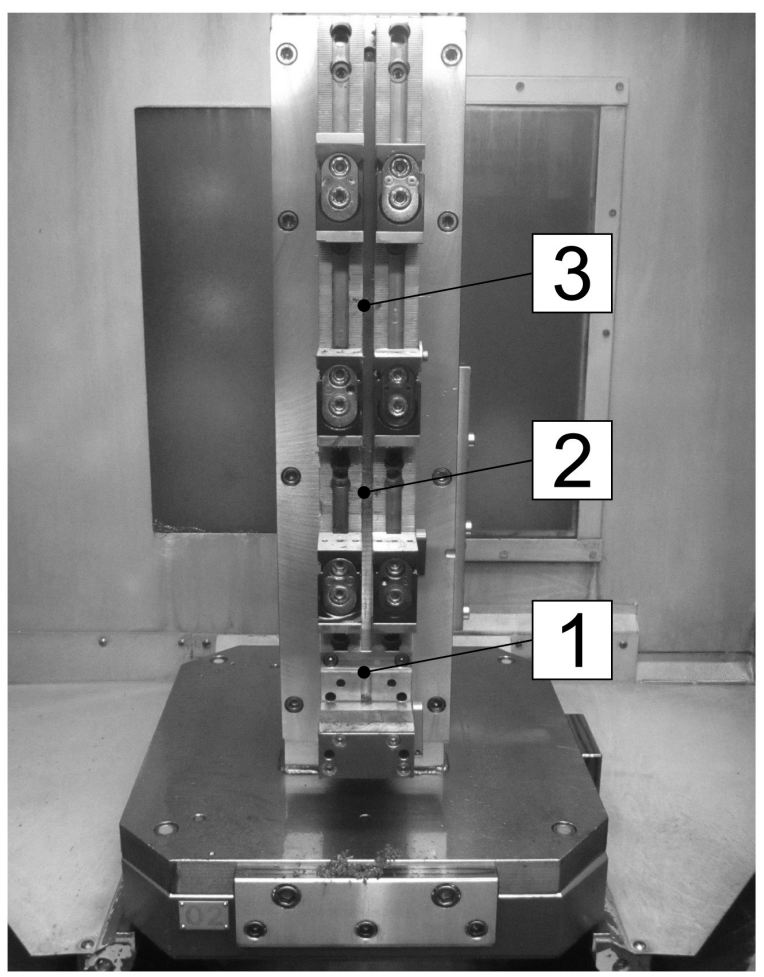

Fig. 6. Clamping device with three nests

\subsection{Final Results Interpretation}

Investigations on measurements reproducibility and clamping device weakness were performed and conclusion is that only measurements of samples that were clamped in nest no. 1 and those whose surface was degreased are adequate for further researches.

One of significant advantages of $\mathrm{L}_{12}$ orthogonal array is that it could be interpreted in three blocks of $\mathrm{L}_{4}$ orthogonal arrays as shown in Table $4 . \mathrm{L}_{4-1}$ represents experiments that include samples that were machined in nest no. 1. ANOVA for $\mathrm{L}_{4-1}$ results (after degreasing) was performed and both controlled

Table 3. Deviations within measurements

\begin{tabular}{cccccc}
\hline & After CNC & \multicolumn{2}{c}{ After washing } & \multicolumn{2}{c}{ After degreasing } \\
\hline Cylindricity & $R a$ & Cylindricity & $R a$ & Cylindricity & $R a$ \\
\hline$(\max -\min )$ & $(\max -\min )$ & $(\max -\min )$ & $(\max -\min )$ & $(\max -\min )$ & $(\max -\min )$ \\
{$[\mu \mathrm{m}]$} & {$[\mu \mathrm{m}]$} & {$[\mu \mathrm{m}]$} & {$[\mu \mathrm{m}]$} & {$[\mu \mathrm{m}]$} & {$[\mu \mathrm{m}]$} \\
\hline 8.49 & 1.15 & 2.84 & 1.3 & 3.928 & 1.3 \\
\hline
\end{tabular}


factors were recognized as significant in machining bore cylindricity and surface roughness.

Table 4. $L_{12}$ : block interpretation

\begin{tabular}{|c|c|c|c|}
\hline Array & Exp. No. & Array & Exp. No. \\
\hline \multirow{12}{*}{$\mathrm{L}_{12}$} & 1 & \multirow{4}{*}{$\mathrm{L}_{4-1}$} & 1 \\
\hline & 2 & & 4 \\
\hline & 3 & & 7 \\
\hline & 4 & & 10 \\
\hline & 5 & \multirow{4}{*}{$\mathrm{L}_{4-2}$} & 2 \\
\hline & 6 & & 5 \\
\hline & 7 & & 8 \\
\hline & 8 & & 11 \\
\hline & 9 & \multirow{4}{*}{$\mathrm{L}_{4-3}$} & 3 \\
\hline & 10 & & 6 \\
\hline & 11 & & 9 \\
\hline & 12 & & 12 \\
\hline
\end{tabular}

\subsubsection{Regression Model for Cylindricity}

The cylindricity formed in reaming piston bore is evaluated in Table 5. Both control factors were recognized as significant. Regression model for cylindricity is defined with Eq. (1):

$$
\text { Cylindricity }=5.37+0.43 \cdot f+0.33 \cdot n .
$$

Cylindricity regression model shows that cylindricity increases with the increase of feed rate $f$ and spindle speed $n$. The feed rate has the most dominant effect on machining piston bore cylindricity, while spindle speed influence is lower. The Model $F$-value of 229 implies the model is significant. There is only a $4.67 \%$ chance that value this large could occur due to the noise.

Table 5. ANOVA for cylindricity regression model

\begin{tabular}{cccccc}
\hline Source & $\begin{array}{c}\text { Sum of } \\
\text { Squares }\end{array}$ & $d f$ & $\begin{array}{c}\text { Mean } \\
\text { square }\end{array}$ & $F$-value & $\begin{array}{c}p \text {-value } \\
\text { Prob }>F\end{array}$ \\
\hline Model & 1.15 & 2 & 0.57 & 229 & 0.05 \\
\hline A $-f$ & 0.72 & 1 & 0.72 & 289 & 0.04 \\
\hline B - $n$ & 0.42 & 1 & 0.42 & 169 & 0.05 \\
\hline R-Squared & $=0.99$ & & & & \\
\hline
\end{tabular}

\subsubsection{Regression Model for Surface Roughness}

The quality of machined surface generated in reaming piston bore is evaluated in terms of mean surface roughness $(R a)$ values in Table 6. Regression model for surface roughness $R a$ is defined with the Eq. (2):

$$
R a_{\text {average }}=0.75+0.25 \cdot f+0.1 \cdot n \text {. }
$$

Feed rate has the main role in achieving surface roughness. The model F-value of $6.36 \cdot 10^{7}$ implies the model is significant. There is only a $0.01 \%$ chance that value this large could occur deue to the noise.

Table 6. ANOVA for roughness regression model

\begin{tabular}{cccccc}
\hline Source & $\begin{array}{c}\text { Sum of } \\
\text { Squares }\end{array}$ & $d f$ & $\begin{array}{c}\text { Mean } \\
\text { square }\end{array}$ & $F$-value & $\begin{array}{c}p \text {-value } \\
\text { Prob }>F\end{array}$ \\
\hline Model & 0.29 & 2 & 0.15 & $6.36 \cdot 107$ & 0.05 \\
\hline A $-f$ & 0.27 & 1 & 0.25 & $6.36 \cdot 107$ & 0.04 \\
\hline B $-n$ & 0.04 & 1 & 0.04 & $6.36 \cdot 107$ & 0.05 \\
\hline R-Squared & $=1$ & & & & \\
\hline
\end{tabular}

\section{DISCUSSION}

This paper addresses the study of piston bore machining. Experimental planning and process modeling was performed by DOE methodology. Influence of productive and non-productive operations on product quality was performed in parallel, but they could be treated individually.

Process pre-analyses were performed with cause and effect methodology. It represents the first step in determination of productive and non-productive operations influence on product quality. Conclusions on productive operations influence analysis lead to technological window determination, design of experiments and their execution. Experimental results were given as cylindricity and roughness of machined bore. ANOVA of measurements gave information if results could lead in multi-objective optimization strategy or not.

If ANOVA does not confirm significance of process parameters, additional cause and effect analyses are needed, corrective actions must be taken and ANOVA must be repeated. In this study this step was repeated three times, i.e. the loop of nonproductive operations influence, namely washing, degreasing and clamping device were observed.

Results of industrial case study show that this methodology can support clear problem statement and lead to suitable corrective actions.

Conclusions that have been made during investigation are facts that must be obtained in further researches. Precise results of regression models for bore cylindricity and surface roughness are needed; these will lead to optimization strategy of piston bore machining (Fig. 7). 


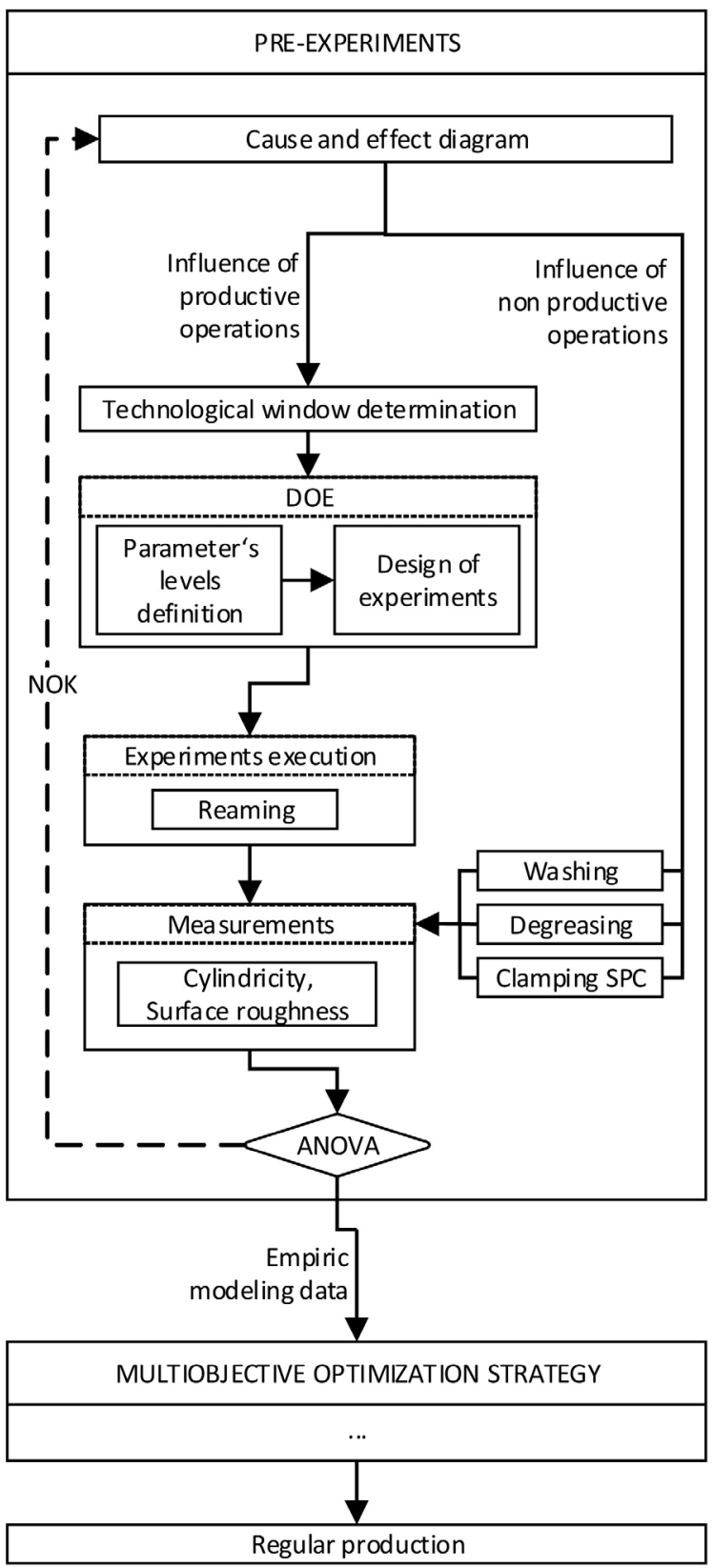

Fig.7. Optimization strategy model

\section{CONCLUSIONS}

Reaming process quality improvement was performed and the following conclusions can be made:

- Surface cleanliness and clamping device rigidity were identified as key non-productive operation factors.

- Surface cleanliness impact was analysed with SEM analysis and was minimized with additional washing and degreasing.
- Surface cleanliness has greater negative effect on bore cylindricity measurements than on surface roughness measurements.

- Clamping device lack of rigidity was minimized with focusing on only one (of three) clamping nest.

- Experimental results of $\mathrm{L}_{12}$ orthogonal array were interpreted with three blocks of $\mathrm{L}_{4}$ orthogonal arrays.

- Regression analyses give models for both productive operations responses (feed rate and spindle speed) under consideration, namely bore cylindricity and surface roughness, and are adequate at $99 \%$ and $100 \%$ confidence level respectively.

- Results show grat feed rate influences on both responses while spindle speed has a smaller effect on bore cylindricity only.

\section{REFERENCES}

[1] Majdič, F., Pezdirnik, J., Kalin, M. (2011). Experimental validation of the lifetime performance of a proportional 4/3 hydraulic valve operating in water. Tribology International, vol. 44, no. 12, p. 2013-2021, D0l:10.1016/j.triboint.2011.08.020.

[2] Montgomery, D., C. (2005). Design and Analysis of Experiments (6th ed.). John Wiley and Sons, Hoboken.

[3] Wen, X., Zhao, Y., Wang, D., Pan, J. (2013). Advanced Monte Carlo and GUM methods for the evaluation of measurement uncertainty of cylindricity error. Precision Engineering, vol. 37, no. 4, p. 856-864, D0l:10.1016/J.precisioneng.2013.05.002.

[4] Stepien, K. (2014). In situ measurement of cylindricity Problems and solutions. Precision Engineering, vol. 38, no. 3, p. 697-701. D0l:10.1016/j.precisioneng.2014.02.007.

[5] Raykar, S.J., D’Addona, D.M., Kramar, D. (2014). Analysis of surface topology in dry machining of EN-8 steel. Procedia Materials Science, vol. 6, p. 931-938, D0l:10.1016/j. mspro.2014.07.163.

[6] Müller, P., Genta, G., Barbato, G., De Chiffre, L., Levi, R. (2012). Reaming process improvement and control: An application of statistical engineering. CIRP Journal of Manufacturing Science and Technology, vol. 5, no. 3, p. 196-201, Dol:10.1016/j. cirpj.2012.07.005.

[7] De Chiffre, L., Tesello, G., Piška, M., Müller, P. (2009). Investigation on capability of the reaming process using minimal quantity lubrication. CIRP Journal of Manufacturing Science and Technology, vol. 2, no. 1, p. 47-54, Dol:10.1016/j. cirpj.2009.08.004.

[8] Korkut, I., Kucuk, Y. (2010). Experimental analysis of the deviation from circularity of bored hole based on the Taguchi method. Strojniški vestnik - Journal of Mechanical Engineering, vol. 6, no. 5, p. 340-346.

[9] Xiao, W., Zi, Y., Chen, B., Li, B., He, Z. (2014). A novel approach to machining condition monitoring of deep hole boring. International Journal of Machine Tools and Manufacture, vol. 77, p. 27-33, D0l:10.1016/j.jmachtools.2013.10.009. 
[10] Tadic, B., Vukelic, D., Miljanic, D., Bogdanovic, B., Macuzic, I., Budak, I., Todorovic, P. (2014). Model testing of fixtureworkpiece interface compliance in dynamic conditions. Journal of Manufacturing Systems, vol. 33, no. 1, p. 76-83, D0I:10.1016/j.jmsy.2013.05.004.

[11] Jose, V., Nebot, A., Liu, J., Subiron, FR. (2014). Quality prediction and compensation in multi-station machining processes using sensor-based fixtures. Robotics and Computer-Integrated Manufacturing, vol. 28, no. 2, p. 208219, D0I:10.1016/j.rcim.2011.09.001.
[12] Theodoris, S., Koutroumbas, K. (1998). Pattern recognition system. Academic Press, San Diego.

[13] Hassan, A., Basksh, M.S.N., Shaharoun, A.M., Jamaluddin, H. (2006). Feature selection for SPC chart pattern recognition using fractional factorial experimental design. Intelligent Production machines and Systems, 2nd $1{ }^{\star} P R O M S$ Virtual International Conference, p. 442-447, D0l:10.1016/B978008045157-2/50079-1.

[14] NFE 66-520, (1994). Couple outil-matiere: Domaine de fonctionnement des outils coupants, vol. 1-6. Anfor, Pariz. 